\title{
A study to compare the efficacy, inadequacy and patient knowledge of pipelle and dilatation and curettage (D\&C) for patients with abnormal uterine bleeding
}

\author{
Meeta Gupta, Poonam Yadav, Narita Jamwal, Vanita Gupta \\ Corresponding author: Dr. Vanita Gupta, Address: F-311, Sainik Colony, Jammu-180011, India; \\ Email : meeta448@gmail.com
}

Distributed under Attribution-Non Commercial - Share Alike 4.0 International (CC BY-NC-SA 4.0)

\begin{abstract}
Objective: We aimed to assess the patient knowledge/choice for subsequent procedure, sampling adequacy, and diagnostic accuracy of Pipelle endometrial sampling and conventional D\&C in patients with abnormal uterine bleeding (AUB). Methods: This study included total 443 women $>40$ years of age, with AUB requiring endometrial evaluation. Pipelle biopsy was done without cervical dilation followed by D\&C. The histopathology of both the procedures was compared, considering histopathology of the D\&C sample as gold standard. Outcomes were compared among the two procedures. Results: Overall accuracy of the Pipelle device was $399(90.67 \%)$. Pipelle device was inadequate in $29(6.55 \%)$ cases. Pipelle was $100 \%$ sensitive and $100 \%$ specific for diagnosis of atrophy, endometritis and endometrial carcinoma each. Pipelle was $100 \%$ sensitive for diagnosis of proliferative endometrium and secretory endometrium each and $96.48 \%$ and $97.92 \%$ specific respectively with excellent AUC of 0.98 and 0.99 respectively. Patients' knowledge/choice for subsequent procedure and procedure associated pain was significantly less for the Pipelle biopsy as compared to D and C. Conclusion: Pipelle is a good, relatively painless, cheap OPD procedure for endometrial aspiration but with the disadvantage of sample inadequacy due to which its routine use remains an enigma for the patient and the doctor.
\end{abstract}

Keywords: Abnormal uterine bleeding, pipelle, D\&C, endometrial sampling.

Menstrual disturbances or nonmenstrual bleeding in women of peri and postmenopausal age group require medical evaluation and if needed endometrial sampling to rule out an objective cause like hyperplasia and carcinoma. Screening of such women becomes important to avoid unnecessary surgeries and sorting the women for medical therapy. With the increasing morbidity and mortality of endometrial carcinoma similar to cervical carcinoma around the world, there would be social and economic benefit from a screening tool as used in the screening of cervical carcinoma (pap smear), that could be used for early detection, leading to earlier treatment of endometrial carcinoma.

For the long time, the gold standard for the assessment of women with abnormal uterine bleeding (AUB) is dilatation and curettage (D \& C) under general anesthesia. However, it has been superseded by other techniques due to its certain disadvantages. 1,2 The other main screening devices for endometrial carcinoma are aspiration devices (the Vabra aspirator), Pipelle, Tao Brush, and SAP-1 brush sampler. ${ }^{1}$ All the devices stated here for evaluation of endometrial changes are associated with limitations or disadvantages for clinical use.

Received: $10^{\text {th }}$ May 2020, Peer review completed: $27^{\text {th }}$ June 2020, Accepted: $29^{\text {th }}$ June 2020.

Gupta M, Yadav P, Jamwal N, Gupta V. A study to compare the efficacy, inadequacy and patient knowledge of pipelle and dilatation and curettage $(\mathrm{D} \& \mathrm{C})$ for patients with abnormal uterine bleeding. The New Indian Journal of OBGYN. 2021; 7(2): 206-11. 
In a developing country as ours, a cheaper screening option for endometrial lesions in women with AUB is the need of the hour. Though D and C is the gold standard, its disadvantages warrant the validation of another routine screening device for endometrial sampling with good pathological accuracy and adequate sampling. Among the various devices, Pipelle seems to be a better option for a country as ours due to being cheap and comparable sample adequacy and accuracy. Thus we aim to evaluate the patient knowledge/choice for subsequent procedure, sampling adequacy and diagnostic accuracy of Pipelle endometrial sampling and conventional $\mathrm{D \& C}$ in patients with abnormal uterine bleeding.

\section{Materials and methods}

A prospective comparative analytical study was conducted over a period of 3 years from April 2016 to March 2019, which included all women $>40$ years of age, presenting with AUB undergoing endometrial evaluation. Pregnant women, women with pelvic inflammatory disease or known malignancy and menopausal women with endometrial thickness $<4 \mathrm{~mm}$ on transvaginal sonography were excluded from the study. The study was approved from the institutional ethical committee (ASCOMS/IEC /RP\&T/2018/316). Informed consent was obtained from the patient before the procedure after explaining regarding the procedure and associated complications.

Sample size for the study was calculated based on the study of Ilavarasi $\mathrm{C}$ et al., ${ }^{2}$ who observed that sensitivity and specificity of pipelle biopsy for endometrial hyperplasia was $64.2 \%$ and $88.8 \%$ and for endometrial carcinoma was $75 \%$ and $100 \%$ respectively. Taking these values as reference, the minimum required sample size with desired precision of $7.5 \%, 90 \%$ power of study and $5 \%$ level of significance is 409 patients. To reduce margin of error, total sample size taken is 443 .

Detailed clinical history of the patient including age, parity, socio-economic status, any hormone therapy was taken. Per speculum examination, pap smear and per vaginal examination was done in detail of all the patients. Transvaginal sonography (TVS) was done to evaluate the endometrial thickness before any intervention was planned. Thyroid and prolactin status was also evaluated.

Pipelle biopsy was taken as an OPD procedure without cervical dilation under full aseptic precautions after informed consent. The same patients were also subjected to conventional D \& C with or without anaesthesia according to patient's pain threshold. The histopathology of both the procedures were sent and the reports were compared. Histopathology of the D\&C sample was considered to be the gold standard.

Post-procedure, the patients were asked -

1. if they had prior knowledge about the procedure

2. If they would voluntarily opt for the procedure for the next time (patient acceptability)

3. To rate the procedural pain on the VAS scale

The outcome measures comprised of histopathology report of the endometrium, complications of the procedure, patient acceptability and the pain associated with the procedure. All the outcomes were compared among the two procedures.

For the data analysis, categorical variables were presented in number and percentage (\%) and continuous variables were presented as mean $\pm \mathrm{SD}$. Diagnostic test was used to calculate sensitivity, specificity, NPV and PPV. The data was entered in MS EXCEL spreadsheet and analysis was done using Statistical Package for Social Sciences (SPSS) version 21.0.

\section{Results}

Among the total of 443 women with AUB who underwent pipelle biopsy and D and $\mathrm{C}$, the mean (St dev) age was 44.65 (3.4) years. Majority of the women were in the age group 40-45 years (Table 1). Majority were multigravida $(n=416)$ and only 27 women were nulligravida. The median duration of symptoms were 7 months among all the patients and majority of them $(n=397)$ presented within a year. The most common symptom was heavy menstrual bleed (HMB) seen in $82 \%$ cases followed by postmenopausal bleed (PMB) in $12 \%$ and intermenstrual bleed (IMB) in $6 \%$ patients.

\begin{tabular}{lll} 
Table 1: Age distribution & & \\
\hline Age distribution in years & Frequency & Percentage \\
\hline $40-45$ & 278 & $62.75 \%$ \\
$46-50$ & 152 & $34.31 \%$ \\
$51-55$ & 7 & $1.58 \%$ \\
$56-60$ & 2 & $0.45 \%$ \\
$61-65$ & 2 & $0.45 \%$ \\
$66-70$ & 1 & $0.23 \%$ \\
$>70$ & 1 & $0.23 \%$ \\
\hline Mean \pm ST dev & $44.65 \pm 3.4$ &
\end{tabular}

The women were evaluated with pipelle biopsy and D and $\mathrm{C}$. The histopathology of $\mathrm{D}$ and $\mathrm{C}$ was considered as gold standard. Overall accuracy of the pipelle device was $399(90.67 \%)$. Pipelle device was inadequate in 29(6.55\%) cases. Among the $29(6.55 \%)$ patients in whom inadequate samples were obtained, thirteen patients were in the proliferative phase, nine were in the secretory phase, three 
The New Indian Journal of OBGYN. 2021 (January-June);7(2)

Table 2: Histopathological results of the specimens

\begin{tabular}{llllll}
\hline Histopathology & D\&C & Pipelle & $\begin{array}{l}\text { Correct } \\
\text { diagnosis }\end{array}$ & $\begin{array}{l}\text { Over } \\
\text { Inadequate }\end{array}$ & $\begin{array}{l}\text { Under } \\
\text { diagnosed }\end{array}$ \\
\hline Proliferative endometrium & 187 & 183 & 174 & 13 & 9 \\
Secretory endometrium & 154 & 151 & 145 & 9 & 6 \\
Simple hyperplasia without atypia & 47 & 40 & 40 & 3 & 0 \\
Complex hyperplasia & 8 & 1 & 1 & 3 & 0 \\
Atrophy & 27 & 27 & 27 & 0 & 0 \\
Simple hyperplasia with atypia & 11 & 3 & 7 & 0 & 0 \\
Endometritis & 7 & 7 & 2 & 0 & 0 \\
Endometrial carcinoma & 2 & 2 & $399(90.67 \%)$ & $29(6.55 \%)$ \\
Total & $443(100 \%)$ & $414(93.45 \%)$ & 0 & $15(3.39 \%)$ \\
\hline
\end{tabular}

patients had simple hyperplasia without atypia, three had sensitive respectively with excellent AUC of 0.95 for simple complex hyperplasia and one had simple hyperplasia with hyperplasia without atypia and fair AUC of 0.6 and 0.65 for atypia. Pipelle device incorrectly diagnosed 15 cases $(7$ cases complex hyperplasia and simple hyperplasia with atypia of complex hyperplasia and 4 cases each of simple respectively (Table 3). After the procedure, D and C let to hyperplasia with atypia and complex hyperplasia) as 9 cases perforation in 2 patients. There was no complication with the of proliferative endometrium and 6 cases of secretory Pipelle biopsy. Post-procedure questionnaire showed that endometrium. However, it correctly diagnosed all cases of prior knowledge of the procedure; patient opting for endometritis, endometrial carcinoma and atrophy (Table 2). subsequent procedure and procedure associated pain was

Table 3: Diagnostic accuracy of pipelle biopsy for various histopathological diagnosis

\begin{tabular}{|c|c|c|c|c|c|}
\hline $\begin{array}{l}\text { Histopathological } \\
\text { diagnosis }\end{array}$ & Sensitivity (95\% CI) & Specificity (95\% CI) & $\operatorname{AUC}(95 \% \mathrm{CI})$ & PPV (95\% CI) & NPV $(95 \%$ CI $)$ \\
\hline $\begin{array}{l}\text { Proliferative } \\
\text { endometrium }\end{array}$ & $\begin{array}{l}100 \% \\
(97.90 \% \text { to } 100.00 \%)\end{array}$ & $\begin{array}{l}96.48 \% \\
(93.43 \% \text { to } 98.38 \%)\end{array}$ & $0.98(0.97$ to 0.99$)$ & $\begin{array}{l}95.08 \% \\
(90.87 \% \text { to } 97.73 \%)\end{array}$ & $\begin{array}{l}100 \% \\
(98.52 \% \text { to } 100.00 \%)\end{array}$ \\
\hline $\begin{array}{l}\text { Secretory } \\
\text { endometrium }\end{array}$ & $\begin{array}{l}100 \% \\
(97.49 \% \text { to } 100.00 \%)\end{array}$ & $\begin{array}{l}97.92 \% \\
(95.54 \% \text { to } 99.23 \%)\end{array}$ & $0.99(0.97$ to 1.00$)$ & $\begin{array}{l}96.03 \% \\
(91.55 \% \text { to } 98.53 \%)\end{array}$ & $\begin{array}{l}100 \% \\
(98.70 \% \text { to } 100.00 \%)\end{array}$ \\
\hline $\begin{array}{l}\text { Simple hyperplasia } \\
\text { without atypia }\end{array}$ & $\begin{array}{l}90.91 \% \\
(78.33 \% \text { to } 97.47 \%)\end{array}$ & $\begin{array}{l}100 \% \\
(99.07 \% \text { to } 100.00 \%)\end{array}$ & $0.95(0.93$ to 0.97$)$ & $\begin{array}{l}100 \% \\
(91.19 \% \text { to } 100.00 \%)\end{array}$ & $\begin{array}{l}99 \% \\
(97.46 \% \text { to } 99.73 \%)\end{array}$ \\
\hline Complex hyperplasia & $\begin{array}{l}20 \% \\
(0.51 \% \text { to } 71.64 \%)\end{array}$ & $\begin{array}{l}100 \% \\
(99.16 \% \text { to } 100.00 \%)\end{array}$ & $0.6(0.55$ to 0.65$)$ & $\begin{array}{l}100 \% \\
(2.50 \% \text { to } 100.00 \%)\end{array}$ & $\begin{array}{l}99.09 \% \\
(97.68 \% \text { to } 99.75 \%)\end{array}$ \\
\hline Atrophy & $\begin{array}{l}100 \% \\
(87.23 \% \text { to } 100.00 \%)\end{array}$ & $\begin{array}{l}100 \% \\
(99.12 \% \text { to } 100.00 \%)\end{array}$ & $1(0.99$ to 1.00$)$ & $\begin{array}{l}100 \% \\
(87.23 \% \text { to } 100.00 \%)\end{array}$ & $\begin{array}{l}100 \% \\
(99.12 \% \text { to } 100.00 \%)\end{array}$ \\
\hline $\begin{array}{l}\text { Simple hyperplasia } \\
\text { with atypia }\end{array}$ & $\begin{array}{l}30 \% \\
(6.67 \% \text { to } 65.25 \%)\end{array}$ & $\begin{array}{l}100 \% \\
(99.15 \% \text { to } 100.00 \%)\end{array}$ & $0.65(0.60$ & $\begin{array}{l}100 \% \\
(29.24 \% \text { to } 100.00 \%)\end{array}$ & $\begin{array}{l}98.41 \% \\
(96.74 \% \text { to } 99.36 \%)\end{array}$ \\
\hline Endometritis & $\begin{array}{l}100 \% \\
(59.04 \% \text { to } 100.00 \%)\end{array}$ & $\begin{array}{l}100 \% \\
(99.16 \% \text { to } 100.00 \%)\end{array}$ & $1(0.99$ to 1.00$)$ & $\begin{array}{l}100 \% \\
(59.04 \% \text { to } 100.00 \%)\end{array}$ & $\begin{array}{l}100 \% \\
(99.16 \% \text { to } 100.00 \%)\end{array}$ \\
\hline $\begin{array}{l}\text { Endometrial } \\
\text { carcinoma }\end{array}$ & $\begin{array}{l}100 \% \\
(15.81 \% \text { to } 100.00 \%)\end{array}$ & $\begin{array}{l}100 \% \\
(99.17 \% \text { to } 100.00 \%)\end{array}$ & $1(0.99$ to 1.00$)$ & $\begin{array}{l}100 \% \\
(15.81 \% \text { to } 100.00 \%)\end{array}$ & $\begin{array}{l}100 \% \\
(99.17 \% \text { to } 100.00 \%)\end{array}$ \\
\hline
\end{tabular}

Pipelle was $100 \%$ sensitive and $100 \%$ specific for significantly less for the pipelle biopsy as compared to D and diagnosis of atrophy, endometritis and endometrial C (Table 4). carcinoma each. Pipelle was $100 \%$ sensitive for diagnosis of

\begin{tabular}{llll} 
Table 4: Comparison of pain and patient knowledge of the procedure & \\
\hline Variables & Pipelle & D and C & P value \\
\hline Nulli gravid VAS score & $4.5 \pm 2$ & $7.9 \pm 2.4$ & $<.0001$ \\
\hline Mean \pm stdev & 4 & 8 & \\
Median & & & \\
Multi gravid VAS score & $2.6 \pm 1.7$ & $5.8 \pm 2.1$ & $<.0001$ \\
\hline Mean \pm stdev & 2 & 6 & \\
Median & $24(5.42 \%)$ & $443(100 \%)$ & $<.0001$ \\
Was the procedure known before? Yes & $57(12.87 \%)$ & $386(87.13 \%)$ & $<.0001$ \\
Will you opt for the procedure for the next time & & & \\
\hline
\end{tabular}

\section{Discussion}

Abnormal uterine bleeding is one of the most commonly faced menstrual problems, which is accountable for $33 \%$ of outpatient referrals, comprising $69 \%$ of referrals in the perimenopausal and postmenopausal age group. The age of $\geq 40$ years is a known risk factor for endometrial diseases; therefore, in women with abnormal uterine bleeding, it is proliferative endometrium and secretory endometrium each and $96.48 \%$ and $97.92 \%$ specific respectively with excellent AUC of 0.98 and 0.99 respectively. On the other hand, pipelle was $100 \%$ specific for diagnosis of simple hyperplasia without atypia, complex hyperplasia and simple hyperplasia with atypia each and $90.91 \%, 20 \%$ and $30 \%$ an indicator for biopsy. This would help in offering medical or conservative treatment and avoidance of unnecessary radical surgery. ${ }^{2,3}$ When compared to our study, some of the studies studied both Pipelle and D \& C ; ${ }^{3-9}$ some studied only Pipelle; ${ }^{2,10,11}$ and some studied different endometrial 
sampling devices such as D\&C, pipelle, Ryle suction and hysteroscopic guided biopsy, ${ }^{12}$ and aspiration devices (such as the Vabra aspirator), Pipelle, Tao Brush, and SAP-1 device. ${ }^{1}$

In our study, pipelle was found to be inadequate in $6.55 \%$ cases whereas $\mathrm{D}$ and $\mathrm{C}$ was adequate in all patients. As reported by a previous study by Rauf et al., ${ }^{6} \mathrm{D} \& \mathrm{C}$ procedure was adequate in all cases while pipelle was found to be inadequate in $2 \%$ cases, which is less than our study. Abdelazim et al., ${ }^{3}$ also reported less number of adequacies as they found that $100 \%$ of the samples obtained by conventional D\&C, whereas $97.9 \%$ of the samples obtained by the pipelle were adequate for histopathological examination. Farzaneh et al, ${ }^{4}$ reported that pipelle was found to be inadequate in $12 \%$ cases and in $2 \%$ cases in D\&C procedure. Other studies reported inadequacy of pipelle in the range of $2 \%$ to $28.8 \%{ }^{5,9,11-13}$

Among those which were inadequate in pipelle (no endometrial tissue in the specimen received), D and C confirmed their diagnosis. This suggests the role of additional procedure to supplement the findings of pipelle in the current scenario. The inadequacy was seen among the cases of benign endometrium, hyperplasia and atypia without any case of endometritis, endometrial carcinoma and atrophy. We hypothesize that inadequacy with pipelle may be due to less expertise as the procedure is relatively new and is not routinely used. Rauf et al., ${ }^{6}$ found that two patients who had inadequate sample were due to associated pain (cervical stenosis) and atrophic endometrium (postmenopausal female). Ilavarasi et al., ${ }^{2}$ reported that in $22.1 \%$ patients inadequate samples were obtained; out of these patients, seven patients had continuous $\mathrm{P} / \mathrm{V}$, endometrial polyp was noted in five patients, atrophic endometrium in four patients, an enlarged uterus with difficult negotiation of the pipelle device into the uterine cavity in four patients, and three patients were in the early proliferative phase.

In our study, the diagnostic accuracy, sensitivity, specificity, PPV and NPV of Pipelle for proliferative endometrium were $90.67 \%, 100 \%, 96.48 \%, 95.08 \%$, and $100 \%$, respectively; for secretory endometrium were $100 \%$, $97.92 \%, 96.03 \%$, and $100 \%$, respectively; for simple hyperplasia without atypia $90.91 \%, 100 \%, 100 \%$, and $99 \%$, respectively; for complex hyperplasia were $20 \%, 100 \%$, $100 \%$, and $99.09 \%$, respectively; for simple hyperplasia with atypia was $30 \%, 100 \%, 100 \%$ and $98.41 \%$ respectively and for atrophy, endometritis and endometrial carcinoma were $100 \%, 100 \%, 100 \%, 100 \%$, respectively.

Comparable to our study, Abdelazim et al., ${ }^{3}$ found that Pipelle device had $100 \%$ sensitivity, $100 \%$ specificity and $100 \%$ predictive values for diagnosing endometrial hyperplasia, endometrial carcinoma, proliferative and secretory endometrium. Ilavarasi et al., ${ }^{2}$ reported lesser accuracy of pipelle as compared to our study as the sensitivity, specificity, PPV and NPV, and accuracy of pipelle biopsy for endometrial hyperplasia was $64.2 \%$, $88.8 \%, 94.1 \%, 85.5 \%$, and $47.3 \%$ and for endometrial carcinoma was $75 \%, 100 \%, 100 \%, 97.9 \%$, and $98 \%$, respectively. Demirkiran et al., ${ }^{13}$ also reported less accuracy of pipelle as sensitivity in detection of hyperplasia and aytpia was $67 \%$ and $75 \%$, respectively. Thus with the increasing and cautious use of pipelle in the suspected cases of endometritis, carcinoma and atrophy (where less sample was reported in previous studies), the diagnostic accuracy and adequacy in them was exceedingly good in our study. Based on the findings we suggest the frequent use of the pipelle as an adjunct to $\mathrm{D} \& \mathrm{C}$ to increase its accuracy, comparability and expertise in performing the procedure over time.

Pipelle is a silastic curette; it does not need a tenaculum or straightening of cervical fundus axis due to its flexibility. General anesthesia is not required. The endometrial tissue is taken by creating a vacuum into the plastic tube and the initial part of the tube is cut and sent for histopathology. D \& $\mathrm{C}$ needs hospitalization, anesthesia, and problem of postoperative pain. We found perforation in 2 patients undergoing $\mathrm{D}$ and $\mathrm{C}$ and no complications in pipelle biopsy. The pain rating on the VAS scale was significantly lower for pipelle as compared to $\mathrm{D}$ and $\mathrm{C}(\mathrm{P}<0.0001)$ It was more for nulligravida and less for multigravida due to the distention of the cervix and multiple manipulations of the uterus during the pregnancy in the multigravida. Similar results were reported by Rauf et al., ${ }^{6}$ as in pipelle group, $92 \%$ patients experienced no discomfort, with only $2 \%$ experienced severe pain and $6 \%$ experienced mild pain, which was less than observed in D\&C group where $45 \%$ patients experienced postoperative moderate and 5\% experienced severe pain up to 9 on VAS and required postoperative analgesia. On the contrary, Moghaddam et al., 5 reported that pain was less in D\&C group (1.65 vs 3.41, $\mathrm{P}<0.05$ ); whereas Abdelazim et al., ${ }^{3}$ Rezk et al., ${ }^{8}$ and Singh P et al., ${ }^{11}$ found no intraoperative and postoperative complication.

In our study, significantly less number of patients 24 $(5.42 \%)$ had a prior knowledge about the pipelle biopsy as 
compared to $\mathrm{D}$ and $\mathrm{C}(100 \%)$. Though the pain rating among the patients undergoing pipelle was significantly less, only 57(12.87\%) patients opted for pipelle for the future as against 386(87.13\%) who opted for $\mathrm{D}$ and $\mathrm{C}(\mathrm{P}<0.0001)$. The reason being less knowledge and awareness about the procedure and a lower adequacy rate with Pipelle biopsy which increases the chances of missing the diagnosis. Previous studies reported different results regarding patient views about the procedure. Rezk et al., ${ }^{8}$ reported results contrary to our study as both procedures were comparable in terms of the overall satisfaction rate and the advisability of the procedure to other women; whereas, Rauf et al., ${ }^{6}$ found that pipelle's acceptability was (98\%) that was more than D\&C group (34\%). Demirkiran et al., ${ }^{13}$ also mentioned that pipelle as an acceptable outpatient method for evaluation of endometrial pathology.

Among the other aspiration devices, the Vabra aspirator is cheap, can be used on an OPD basis and suffers from fewer complications than D and C. In comparison to pipelle, it has shown less success rate and higher average cost per patient. ${ }^{1}$ In an outpatient setting, Tao Brush can be used without anesthetic; it is easy to use and well tolerated by women. In comparison to pipelle, it is found to be less painful with less specimen insufficiency. Its specimen satisfaction is 89.9 to $100 \%$, and the pathological accuracy is 91.0 to $96.0 \%$, but it suffers from disadvantages of higher cost, inadequacy to distinguish simple hyperplasia without atypia from disordered proliferative endometrium or to diagnose endometrial polyps, and not collecting enough endometrial cells of the uterine horns because of its round configuration. SAP-1 brush sampler device was patented and used in China in 2001. For screening endometrial carcinoma and its precursors, it can be a reliable method because of its high accuracy of endometrial cytology (92.4\%). But, to date there are not many clinical trials that support the feasibility of the SAP-1 device. In addition, like the Tao Brush, in theory, the SAP-1 device also does not adequately collect cells in the uterine horn. Pipelle biopsy was introduced by Cornier in 1984 and is one of the most studied biopsy device for women with AUB. In comparison with traditional D\&C, pipelle sampling takes less time with a comparable specimen satisfaction rate. Its pathological accuracy varies for different endometrial lesions but has been found comparable to D and C. ${ }^{1}$

Limitations of the study: We have not compared two procedures in terms of cost, which could be a main factor in developing country as ours where a large proportion of patients belong to lower socioeconomic class. Endometrial biopsy or hysterectomy was not taken as gold standard for assessing the diagnostic accuracy. The previous experience of the doctor in performing the procedure was not taken in to account as it might be related to the inadequacy rate.

\section{Conclusion}

In conclusion, Pipelle is a good, relatively painless cheap OPD procedure for endometrial aspiration with good acceptability but suffers from disadvantage of a relatively high sample inadequacy and less patient knowledge and awareness. It is recommended to increase its awareness among the practitioners and the general public to decrease the sample inadequacy and increase the diagnostic accuracy. However, as of now D and C shall continue as the standard investigation for AUB.

\section{Conflict of interest: None. Disclaimer: Nil.}

\section{References}

1. Du J, Li Y, Lv S, Wang Q, Sun C, Dong X, et al. Endometrial sampling devices for early diagnosis of endometrial lesions. J Cancer Res Clin Oncol. 2016;142(12): 2515-22.

2. Ilavarasi Cr, Jyothi G, Alva N. Study of the efficacy of pipelle biopsy technique to diagnose endometrial diseases in abnormal uterine bleeding. J Life Health. 2019;10(2):75.

3. Abdelazim IA, Aboelezz A, AbdulKareem AF. Pipelle endometrial sampling versus conventional dilatation \& curettage in patients with abnormal uterine bleeding. J Turkish-German Gynecol Assoc. 2013;14:1-5.

4. Farzaneh F, Mohammadi M, Niazi A, Eamaeilzadeh A, Rezaei S. Comparison of efficacy of Pipelle biopsy with dilatation and curettage. Zahedan J Res Med Sci. 2017;19(12):e10892.

5. Moghaddam TG, Hedayatifar F, Nouri B. Comparingthe pipelle with dilatation and curettage (D\&C) in diagnostic power of sampling for evaluating the patients with abnormal uterine bleeding. Int J Med Invest 2018; 7(1); 56-67.

6. Rauf R, Shaheen A, Sadia S, Waqar F, Zafar S, Sultana $S$, Waseem S. Outpatient endometrial biopsy with Pipellevs diagnostic dilatation and curettage. J Ayub Med Coll Abbottabad. 2014; 26(2):145-8.

7. Rachamallu L, Bhavani V, Byna P. Histological correlation of pipelle endometrial sampling with 
The New Indian Journal of OBGYN. 2021 (January-June);7(2)

dilatation and curettage in abnormal uterine bleeding. Int J Reprod Contracept Obstet Gynecol. 2015; 4:1324-9.

8. Rezk M, Sayyed T, Dawood R. The effectiveness and acceptability of Pipelle endometrial sampling versus classical dilatation and curettage: a three-year observational study. Gynecol Obstet Invest. 2016; 81(6): 537-42.

9. Fakhar S, Saeed G, Khan AH, Alam AY. Validity of pipelle endometrial sampling in patients with abnormal uterine bleeding. Ann Saudi Med. 2008; 28(3):188-91.

10. Batig AL, Elliott D, Rumjahn H, Keylock J, Chinn M, Chow GE. Pipelle endometrial sampling in the evaluation of abnormal first trimester pregnancies. Mil Med. 2014;179(9):1030-5.

11. Singh P. Abnormal uterine bleeding- evaluation by endometrial aspiration. Journal of Midlife Health. 2018; 9: $32-5$.

12. Edessy M, Saleh H, Abdelhady H, Abdelsattar M, Salah H. Diagnostic accuracy of endometrial sampling devices for abnormal uterine bleeding in Egyptian mature woman. Int J Adv Res Biol Sci. 2014;1(7):173-9.

13. Demirkiran F, Yavuz E, Erenel H, Bese T, Arvas M, Sanioglu C. Which is the best technique for endometrial sampling? Aspiration (pipelle) versus dilatation and curettage (D\&C). Arch Gynecol Obstet. 2012; 286(5):1277-82.

\section{Meeta Gupta ${ }^{1}$, Poonam Yadav², Narita Jamwal ${ }^{3}$, Vanita} Gupta $^{4}$

${ }^{1}$ Associate Professor, Department of Obstetrics and Gynaecology, ASCOMS, Jammu (J and K), India;

${ }^{2}$ Associate Professor, Department of Obstetrics and Gynaecology, S.N Medical college, Agra (U.P), India;

${ }^{3}$ Assistant Professor, Department of Obstetrics and Gynaecology, ASCOMS, Jammu (J and K), India;

${ }^{4}$ Professor and Head, Department of Anatomy, ASCOMS, Jammu (J and K), India. 